\title{
Loneliness Experience Questionnaire
}

\author{
EA Manakova* \\ Department of Psychology, Russia
}

*Corresponding author: Manakova Ekaterina Alexandrovna, Associate Professor at the Department of Psychology, FSBEI

HE “Altai State Pedagogical University”, 656031, Altai Territory, Barnaul, st. Youth, 55, Russia

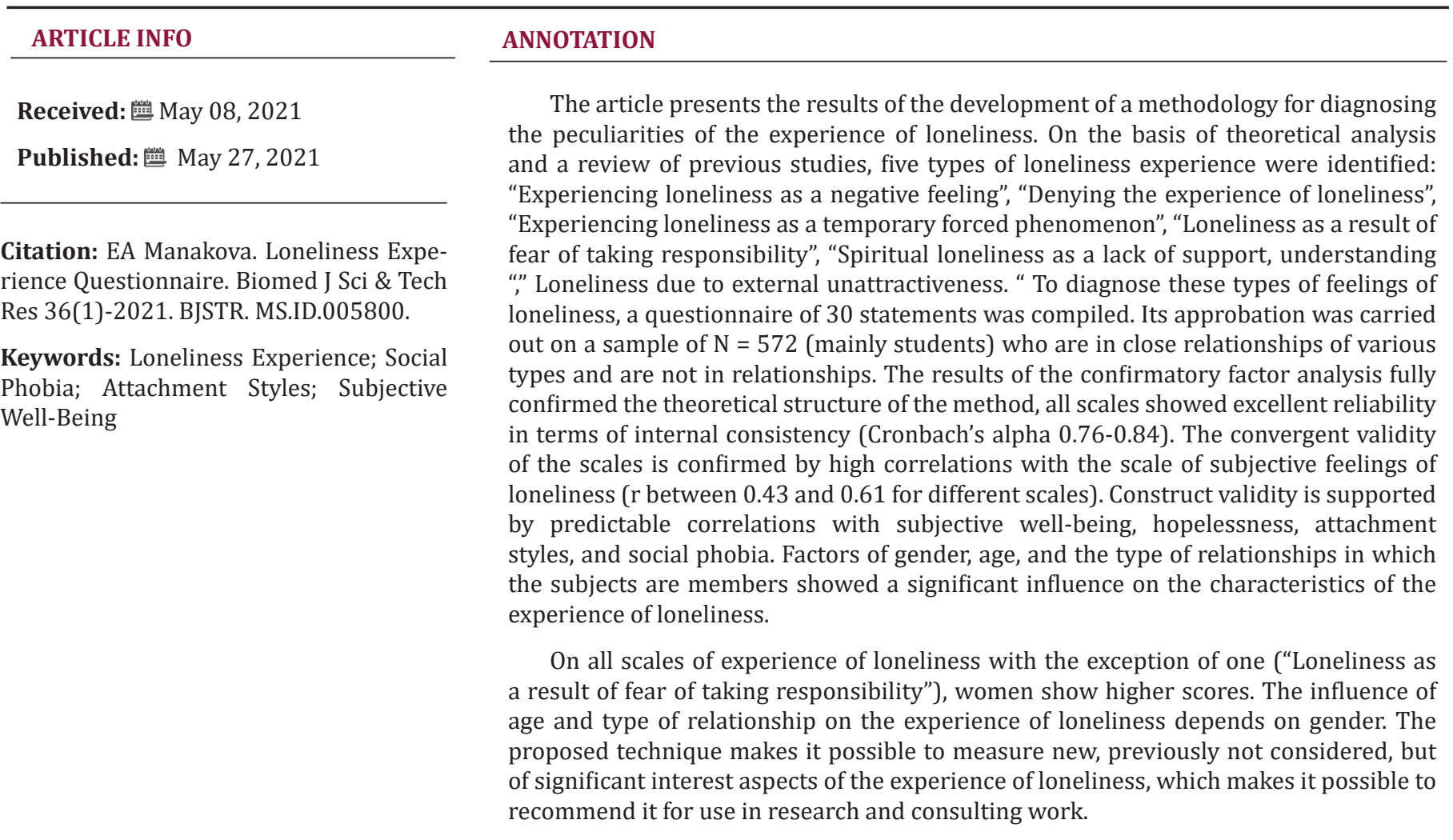

\section{Theoretical Basis of Research}

Today loneliness has become one of the most pressing problems of modern society. According to the data provided by the AllRussian Center for the Study of Public Opinion (VTsIOM), in recent years there has been an increase in the number of single people in their place of residence. The share of such respondents is the highest among 18-24-year-olds (90\%). Loneliness is felt by $13 \%$ of Russians - these are, first of all, women (16\%) Statistics [1]. It is worth noting that youthful loneliness is becoming widespread. This is primarily due to the fact that it is during this period that the need for cooperation with people increases, the search for a life partner becomes relevant, a feeling of intimacy with certain people appears, and ties with one's social group are strengthened. So, according to E. Erikson, dissatisfaction with such relationships or their absence can increase loneliness Erikson [2]. I.N. Ishmukhametov points out that the experience of loneliness is most clearly manifested in adolescence due to an unstable social position, individualization of activities and formalization of social roles, while the need for close relationships remains unsatisfied Ishmukhametov [3]. Thus, loneliness reflects negative experiences associated with dissatisfaction with relationships with others due to an objective or subjectively perceived deficit of such relationships. The experience of loneliness depends only on subjective ideas about the presence and quality of close relationships. 
This means that the formal existence of a relationship (for example, with a spouse) does not indicate the absence of feelings associated with loneliness Mikulincer [4]. Acting as a subjective state, the experience of loneliness can be rather loosely related to the real existence and quality of relationships. At the same time, it should be noted that the style of attachment in relationships affects the subjective feeling of loneliness and is one of the factors of its occurrence. Studies of parent-child relationships have shown that children with anxious attachments are more prone to loneliness than children with avoidant attachments because they are more acutely concerned with unmet need for love and security Berlin, et al. [5]. It is common for children with avoidant attachment to deny or suppress their need for love, which leads to less awareness and severity of feelings associated with loneliness. Unsurprisingly, a similar relationship between attachment characteristics and loneliness persists into later ages. A number of studies in young men and women in marital or premarital relationships have concluded that both restless and avoidant attachment styles are closely related to subjective feelings of loneliness Mikulincer [4]. In a study on married couples, it was shown that individuals with insecure attachment lower the quality of their relationships and higher assess their level of loneliness Givertz, et al. [6].

T.L. Kryukova notes that with destructive attachment to a partner (an unreliable type of attachment, accompanied by a high level of stress, "growing together" with a partner, fear of losing him, jealousy, and high anxiety), the suffering from loneliness and its overestimation in relationships grow. The author points out that men who are married over time more often recognize their loneliness, accepting it as inevitability, and women more often than men focus on the negative aspects of the experience in connection with high expectations from interpersonal relationships and the need to express feelings Kryukova [7]. Another equally important component of the emotional side of experiencing loneliness is subjective well-being. D. Casioppo and colleagues in longitudinal studies have identified the relationship between the experience of loneliness and subjective well-being Cacioppo [8]. Scientists have shown that subjectively assessed loneliness is a more important predictor of negative health effects than real (objective) social isolation. The importance of close relationships at any age is determined by their influence on the emotional well-being and psychological comfort of the individual Pierce, et al. [9], satisfaction of the basic need for affection and intimacy in relationships Myers [10], the possibility of close and confidential communication. E.N. Osin and D.A. Leont'ev also note in their study high rates of loneliness experience in persons with a low level of subjective wellbeing and an actual crisis of loss of meaning Osin [11].

Loss of meaning and a sense of hopelessness lead to the following psychological problems: feeling unwell, suicidal behavior, addictions, etc. Also L. Anderson Andersson, et al. [12,13], P. Tikkainen Tiikkainen, et al. [14] described the relationship between the experience of loneliness and suicide or attempted suicide. Interesting data were obtained by I.M. Slobodchikov in the study of the subjective perception of the experience of loneliness in people of different age categories, including the period of adolescence. The author presents a synonymous number of the concept of "loneliness" It includes concepts of a phobic and traumatic nature hopelessness, helplessness, defenselessness, fear, etc. Slobodchikov [15]. J. Kupersmidt, K. Sigda, M. Wegler and K. Sedikides also pointed out that a lonely person experiences emotional problem, including social anxiety, low self-esteem, as well as shyness and isolation, decreased contact with others Kupersmidt, et al. [16]. Analysis of the above factors, which are tendencies of the emergence of the experience of loneliness (subjective well-being, attachment style, hopelessness, social anxiety) showed that they are not sufficiently disclosed in the context of various types of loneliness, especially during adolescence. Research on the experience of loneliness in developmental psychology refers to adolescence, adulthood, or old age.

The methodological significance of the theories of the experience of loneliness (the theory of loneliness by D. Russell and L. Peplo, the theoretical and clinical approach of A. Beck, etc.) and modern research is that on the basis of their analysis it became possible to define loneliness in its subjective aspect, as well as determination of their own positions regarding this experience. Based on the basic psychological concepts that consider loneliness as a non-pathological state, a generalizing definition of loneliness was developed in the context of the level of satisfaction of the social needs of the individual. Loneliness is a negative socio-psychological experience arising as a result of inadequate satisfaction of the social needs of the individual, the consequence of which is the feeling of oneself as abandoned, unnecessary; in which there is a loss of emotional connection with others. The use of the term "experience" in relation to loneliness is associated with its definition within the framework of the theory of experience of F.Ye. Vasilyuk, who described this process as internal, complex, multi-stage and leading to the transformation of the inner world; perceived component of feeling Vasilyuk [17]. The basis for the development of a multidimensional questionnaire on the experience of loneliness was the results of an earlier analysis of the content of various approaches and methods for diagnosing loneliness Manakova [18].

With the help of cluster analysis, it was shown that the content of the majority of questionnaires popular in our country for measuring loneliness during generalization forms the following categories: the experience of loneliness as a negative feeling, the denial of the experience of loneliness as a negative feeling, and the experience of loneliness as a temporary forced phenomenon. On the basis of the structure obtained and the theoretical analysis of this problem of experience, three additional types of the experience of loneliness in adolescence were identified: loneliness as a result of the fear of taking responsibility for others; spiritual loneliness 
as a lack of support, understanding; loneliness due to external unattractiveness. Based on the results of the dissertation research, it can be assumed that people experiencing loneliness as a negative feeling are characterized by the following personal characteristics: anxiety, suspiciousness, and self-doubt. They often feel helpless, incompetent, and weak. They have a low tolerance for negative experiences and an increased sensitivity to rejection or failure. A typical emotion for these people is dysphoria (a combination of anxiety and sadness). Anxiety is usually generated by fear of criticism and the likelihood of breaking up a dependent relationship, while sadness is generated by a lack of close relationships and success.

They are characterized by a certain introversion and awareness of problems through the pessimistic prism of assessing their prospects. Thus, there is an understatement of the positive or encouraging aspects. These people usually have high expectations in a wide range of situations - that things will go badly in the end, or that success will inevitably turn out to be failure. As a rule, there is a fear of making a mistake that will lead to humiliation or getting into a problem situation. Due to the exaggeration of the likelihood of possible negative outcomes, these people are often prone to anxiety, vigilance, complaint, and indecision. In social groups, they tend to keep apart, the main trauma or threat is associated with rejection and rejection in connection with an internal specific motivational conflict between an intense desire to make contact and a subjectively overwhelming excessive fear of this contact. E.N. Osin and D.A. Leontyev note that the fear of rejection reveals a pronounced positive correlation with dependence on communication Osin [19]. People who deny the experience of loneliness as a negative feeling have a certain autonomy; other people, as a rule, do not interest them. They do not allow closeness, seeking to protect personal independence and solitude, referring to themselves as self-sufficient loners.

They highly appreciate such personality traits as mobility and independence; the priority is the independent making of any kind of decisions and actions alone. They find other people obsessive and believe that intimacy affects their independence. Their most important interpersonal behavior tactic is to stay as far away from other people as possible. Any attempts to get closer to them are perceived as intrusion or threat. If people with this type of experience find themselves forced to come into close contact, then this causes them a sense of anxiety. They do not tend to express feelings with facial expressions or words. This may give the impression that they lack strong feelings. Social self-isolation is usually determined by a particular personal philosophy, and sometimes by beliefs in the hostility of the environment. Their beliefs are very rigid, they are not able to change their minds themselves, even when objectively necessary. People who experience loneliness as a temporary forced phenomenon tend to relieve themselves of personal responsibility. Since they are convinced that if something does not work out, then you should not show persistence, although you really want to, since there are situations when you need to wait for a more favorable coincidence of circumstances without losses and disappointments.

During the period of forced loneliness, the maximum concentration on oneself occurs, anxiety arises about one's state of mind, which violates emotional well-being. The rethinking of their own image explains the belief in such people that during a period of forced loneliness, a person will definitely feel guilt (shame, regret) for the pain inflicted on another, for their bad habits, for a lack of general culture. Loneliness as a result of the fear of taking responsibility for others is a fairly common type of experience, both among young women and men. As a rule, these people do not create families and lead a lonely lifestyle, entering into relationships that do not entail any obligations. They do not tend to take an active life position, be in a leadership position and enjoy their own strengths and capabilities. Such people are not ready to cope with responsibility, they feel fear and helplessness from their own failure. Yu.M. In the process of socio-demographic analysis of the experience of loneliness, Cherepukhin identified a number of orientations of the experience of loneliness in a negative form, depending on the marriage relationship. The author pointed out that a large number of people remain single and unmarried. The choice of a lonely lifestyle may be the result of avoiding commitments and problems that arise in marriage and removing responsibility for a partner Cherepukhin [20].

Spiritual loneliness as a lack of support and understanding is often experienced by people who know or can do something that is not clear and not accessible to the majority, moreover, is not appreciated or recognized by them. It is these circumstances that cause misunderstanding, rejection, or neglect on the part of others, incompatibility in the value system. A person for whom it is important to share his knowledge, and who is confident in its effectiveness, in this situation feels unappreciated, ridiculed, and misunderstood. O. M. Krasnikova notes that it is very difficult and scary to be the first, capable, the best and the only one in anything, since there is a high probability of being condemned and ignored by one's contemporaries. The worst thing that can happen to such a person, according to the author, is the renunciation of his vocation. Since vocation is a great responsibility, a person will remember this and will not be able to forgive himself Krasnikova [21]. Loneliness due to external unattractiveness is a very difficult experience, especially in adolescence. Such young men and women are not popular with the opposite sex, they often fall in love with completely inaccessible and indifferent to them. Further, as a rule, they suffer from unrequited feelings and resign themselves to the idea that they will never meet with the person they like.

This circumstance leads to the feeling of being a "black sheep" ", And with an inner conviction of its unattractiveness it becomes a serious psychological problem. When working with such people, 
it is very important to develop their ability to make and receive compliments, emphasize the attractiveness of their physical characteristics, and explore approaches to physical intimacy. The above categories are not statistically independent, but their use for the purposes of multidimensional diagnostics will provide a more complete and meaningful description of the individual characteristics of the experience of loneliness in its various aspects. In this regard, the goal, the goal of the study was the development and testing of a multifactorial questionnaire on the experience of loneliness, the structure of which reflects the considered aspects.

\section{Procedure, Sampling and Research Methods}

In the process of developing the questionnaire, considering the results of previous studies Manakova [18], 72 statements were formulated that reflect the types of loneliness experienced above. In the course of the pilot study, a questionnaire composed of these statements was conducted on a sample of 160 students. Based on the data obtained, a selection of tasks was carried out aimed at maximizing the internal consistency of the scales by eliminating non-working items. The text of the 30 -item questionnaire obtained as a result of this procedure was used further in the course of this study aimed at analyzing the factor structure, reliability, and validity of the method. The sample of this study includes 572 subjects aged from 16 to 28 years $(M=20.58$; $S D=3.43)$, most of whom were students from universities in Barnaul. The distribution of subjects by gender and the type of relationship in which they were at the time of the study is shown in (Table 1). In the course of analyzing the validity of the questionnaire, a set of methods of psychological diagnostics was used. To diagnose the subjective feeling of loneliness, the UCLA scale by D. Russell was used, adapted by I.N. Ishmukhametova Ishmukhametov [3], consisting of 20 statements (examples: "How often do you feel lonely?", "How often do you feel that there are people with whom you can talk?"), Which are evaluated on a 4-point scale ... The reliability of the scale in this study (Cronbach's alpha) was 0.92 .

Table 1: Sample composition by type of close relationship and gender.

\begin{tabular}{|c|c|c|c|}
\hline & Women & Men & Total \\
\hline No relationship & $83(33 \%)$ & $127(51 \%)$ & $210(37 \%)$ \\
\hline Loose relationship & $16(6 \%)$ & $70(28 \%)$ & $86(15 \%)$ \\
\hline Meet & $74(29 \%)$ & $73(29 \%)$ & $147(26 \%)$ \\
\hline Cohabitation & $22(9 \%)$ & $18(7 \%)$ & $40(7 \%)$ \\
\hline Official marriage & $52(21 \%)$ & $21(8 \%)$ & $73(13 \%)$ \\
\hline Divorced & $4(2 \%)$ & $1(0 \%)$ & $5(1 \%)$ \\
\hline Other & $0(0 \%)$ & $11(4 \%)$ & $11(2 \%)$ \\
\hline Total & $251(44 \%)$ & $321(56 \%)$ & 572 \\
\hline
\end{tabular}

To diagnose subjective well-being, we used the "Scale of subjective well-being" technique by A. Bado and G.A. Mendelssohn, adaptation by M.V. Sokolova Sokolova [22]. The scale consists of 17 statements, the agreement with which must be assessed on a seven-point scale from "strongly disagree" to "strongly agree". The reliability of the scale (Cronbach's alpha) in this study was 0.86 . When interpreting indicators on the scale of subjective wellbeing, it is necessary to consider that it is the opposite, that is, high indicators indicate low well-being. The Beck Hopelessness Scale Beck, et al. [23] was used to assess hopelessness as an indicator of distress and suicidal risk. Hopelessness as an experience of despair or extreme pessimism about the future, according to some researchers, is one of the most accurate predictors of the risk of suicide in the long-term Beck, et al. [24]. The scale includes 20 questions assessing negative feelings about the future. In our study, the reliability of the hopelessness scale (Cronbach's alpha) was 0.87. The results of the theoretical analysis showed that among the personality traits that have a significant negative impact on the establishment of close relationships, attachment style and social anxiety occupy an important place. These personality traits were measured in our study to analyze the construct validity of the proposed methodology.

To diagnose the style of attachment, we used the "Questionnaire of attachment to close people" by N.V. Sabelnikova and D.V. Kashirsky Sabelnikova [25]. This questionnaire was based on the Intimate Relationship Experience (ECR) methodology by K. Brennan, S. Clarke and F. Shaver and the two-factor attachment model, in which attachment style is determined by a combination of anxiety about relationships and avoidance of attachment relationships Brennan, et al. [26]. The questionnaire consists of 30 statements, agreement with each of which must be assessed on a scale from 1 to 7 . The reliability of the scales (Cronbach's alpha) in our study was 0.74 for the avoidance scale and 0.82 for the anxiety scale. To assess social anxiety as a probable factor of loneliness, the questionnaire of social anxiety and social phobia was used by O.A. Sagalakova and D.V. Truevtseva Sagalakova [27]. This questionnaire is designed to determine the level of social anxiety and its dominant type, as well as the severity of certain aspects of the manifestation of fear of evaluation in different situations. The methodology consists of 29 points formulated in the form of questions that must be 
answered on a 4-point scale. This technique allows one to obtain an assessment on five scales that characterize individual aspects of the manifestation of social anxiety, as well as an integral indicator reflecting its general level. In this study, only the general indicator of social anxiety and social phobia was used. The safety factors for this indicator (Cronbach's alpha) were 0.91.

\section{Results}

\section{Descriptive Statistics and Questionnaire Reliability}

The distribution on all scales differs significantly from the normal one (the values of the Shapiro-Wilk test are from 0.69 to 0.94 , all are significant at $\mathrm{p}<0.001$ ). The values of the skewness coefficient on all scales are positive (from 0.68 on a scale of 3 to 2.09 on a scale of 6 ), which indicates the prevalence of relatively low values. This fact reflects the relative rarity of intense experiences associated with loneliness, especially the experience of loneliness as a consequence of external unattractiveness (scale 6). Assessment of the reliability of the scales using Cronbach's alpha coefficients showed that all scales are characterized by high internal consistency (Table 2).

Table 2: Descriptive statistics, reliability and intercorrelations of scales loneliness questionnaire.

\begin{tabular}{|c|c|c|c|c|c|c|c|}
\hline Scales / Indicators & Scale 1 & Scale 2 & Scale 3 & Scale 4 & Scale 5 & Scale 6 & $\begin{array}{l}\text { Overall } \\
\text { Indicator }\end{array}$ \\
\hline Scale 1. Experiencing loneliness as a negative feeling & - & & & & & & \\
\hline Scale 2. Denying the experience of loneliness & $0.36^{* * *}$ & - & & & & & \\
\hline $\begin{array}{l}\text { Scale 3. Experiencing loneliness as a temporary forced } \\
\text { phenomenon }\end{array}$ & $0.42^{* * *}$ & $0.68^{* * *}$ & - & & & & \\
\hline $\begin{array}{l}\text { Scale } 4 \text {. Loneliness as a result of fear of taking responsibility } \\
\text { for others }\end{array}$ & $0.38^{* * *}$ & $0.70^{* * *}$ & $0.49^{* * *}$ & - & & & \\
\hline $\begin{array}{l}\text { Scale 5. Spiritual loneliness as a lack of support, } \\
\text { understanding }\end{array}$ & $0.64^{* * *}$ & $0.55^{* * *}$ & $0.54^{* * *}$ & $0.58^{* * *}$ & - & & \\
\hline Scale 6. Loneliness due to external unattractiveness & $0.50^{* * *}$ & $0.40^{* * *}$ & $0.34^{* * *}$ & $0.49^{* * *}$ & $0.60^{* * *}$ & - & \\
\hline General indicator & $0.69 * * *$ & $0.82^{* * *}$ & $0.78^{* * *}$ & $0.79 * * *$ & $0.83^{* * *}$ & $0.69^{* * *}$ & - \\
\hline Average & 7.69 & 8.86 & 10.81 & 7.78 & 7.81 & 7.03 & 49.97 \\
\hline \multicolumn{8}{|l|}{ Standard } \\
\hline deviation & 3.31 & 4.05 & 4.41 & 3.62 & 3.50 & 3.09 & 16.98 \\
\hline Reliability (Alpha Cronbach) & 0.76 & 0.84 & 0.79 & 0.82 & 0.85 & 0.81 & 0.93 \\
\hline
\end{tabular}

Note: Significance level of correlation coefficients: ${ }^{* * *}-\mathrm{p}<0.001$

\section{Factor Structure}

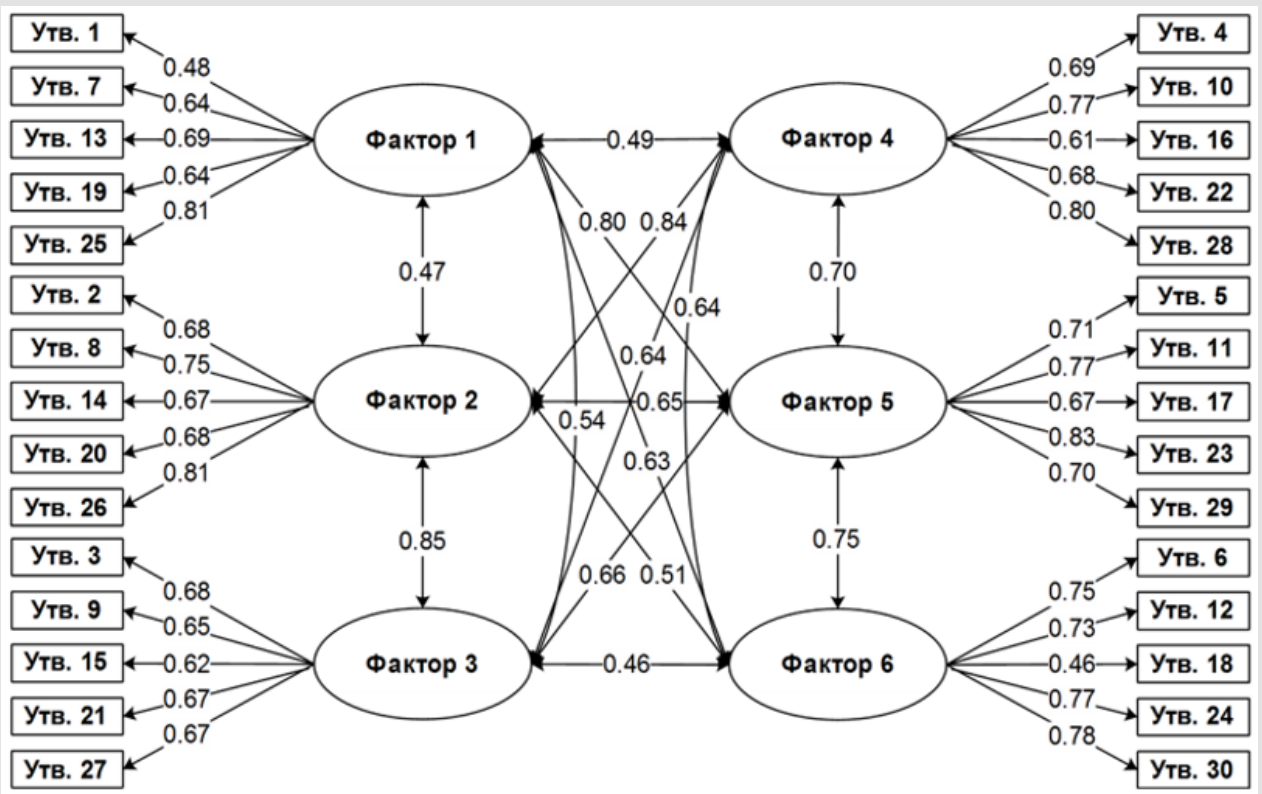

Figure 1: The factorial model of the questionnaire on the experience of loneliness. All the given coefficients are standardized and statistically significant at $\mathrm{p}<0.01$ (The numbering of the factors corresponds to the numbering of the scales; for the names of the scales, (Table 2). 
Based on the theoretical structure of the questionnaire, a factorial model was built that includes six interrelated factors corresponding to the scales of the experience of loneliness. The assessment of the conformity of this model to the obtained data was carried out using confirmatory factor analysis in the Mplus 7 program using the MLR algorithm, which makes it possible to obtain robust (stable with respect to deviations from the normal distribution) estimates. As a result of the analysis of the model, indicators were obtained that testify to the good correspondence of the theoretical model to the obtained data: $\chi 2=696.308$; $\mathrm{df}$ = 390; $\mathrm{p}<0.001 ; \mathrm{CFI}=0.939 ; \mathrm{NNFI}=0.932 ; \mathrm{RMSEA}=0.037$; confidence interval for RMSEA: 0.033-0.041; $N=574$. In a visual form, the resulting model is shown in (Figure 1). To study the factor structure of the second level, an analysis of the main components of the total assessments on six scales was carried out. The results of the analysis testify in favor of a one-factor solution: an eigenvalue exceeding one was obtained only for the first factor, while the factor loadings on the common factor for all scales were at least 0.70 . This means that at the top level of the structure of the questionnaire, all of its scales form a single factor in the experience of loneliness.

\section{Validity}

Table 3: Correlation coefficients of scales of loneliness experience with subjective feeling of loneliness according to D. Russell and M. Ferguson scale $(\mathrm{N}=572)$.

\begin{tabular}{|l|c|}
\hline & $\begin{array}{c}\text { Subjective } \\
\text { sensation } \\
\text { loneliness }\end{array}$ \\
\hline Scale 1. Experiencing loneliness as a negative feeling & $0.57^{* * *}$ \\
\hline Scale 2. Denying the experience of loneliness & $0.47^{* * *}$ \\
\hline $\begin{array}{l}\text { Scale 3. Experiencing loneliness as a temporary forced } \\
\text { phenomenon }\end{array}$ & $0.44^{* * *}$ \\
\hline $\begin{array}{l}\text { Scale 4. Loneliness as a result of fear of taking } \\
\text { responsibility for others }\end{array}$ & $0.43^{* * *}$ \\
\hline $\begin{array}{l}\text { Scale 5. Spiritual loneliness as a lack of support, } \\
\text { understanding }\end{array}$ & $0.61^{* * *}$ \\
\hline Scale 6. Loneliness due to external unattractiveness & $0.42^{* * *}$ \\
\hline \multicolumn{1}{|c|}{ General indicator } & $0.63^{* * *}$ \\
\hline
\end{tabular}

Note: Significance level: ${ }^{* *}-\mathrm{p}<0.001$

To analyze the convergent validity of the method, a correlation analysis of its scales with estimates on the scale of subjective feelings of loneliness by D. Russell and M. Ferguson was carried out. The correlation coefficients shown in (Table 3) indicate that all the described types of loneliness experience are more characteristic of persons experiencing a strong subjective feeling of loneliness. At the same time, the scales "Experiencing loneliness as a negative feeling" and "Spiritual loneliness as a lack of support, understanding", as well as the total indicator, show the closest connection with the subjective feeling of loneliness. The analysis of construct validity was aimed at testing hypotheses about the relationship of the experience of loneliness with other mental phenomena that act as probable causes or consequences of the experience of loneliness. Considering the results of theoretical analysis, it was suggested that various forms of experiencing loneliness are associated with indicators of psychological wellbeing of the individual and personality traits that have a significant impact on the establishment of close relationships. The results of the analysis of the relationship between the experience of loneliness and indicators of psychological well-being are presented in (Table 4).

Table 4: Correlation Coefficients of Loneliness Experience Scales with scales of subjective well-being and hopelessness $(\mathrm{N}=572)$.

\begin{tabular}{|l|c|c|}
\hline \multicolumn{1}{|c|}{ Sample size N } & $\begin{array}{c}\text { Scale } \\
\text { subjective } \\
\text { well-being }\end{array}$ & $\begin{array}{c}\text { Scale } \\
\text { hopelessness }\end{array}$ \\
\hline $\begin{array}{l}\text { Scale 1. Experiencing loneliness as a } \\
\text { negative feeling }\end{array}$ & $0.52^{* * *}$ & $0.27^{* * *}$ \\
\hline $\begin{array}{l}\text { Scale 2. Denying the experience of } \\
\text { loneliness }\end{array}$ & $0.42^{* * *}$ & $0.27^{* * *}$ \\
\hline $\begin{array}{l}\text { Scale 3. Experiencing loneliness as a } \\
\text { temporary forced phenomenon }\end{array}$ & $0.34^{* * *}$ & -0.01 \\
\hline $\begin{array}{l}\text { Scale 4. Loneliness as a result of fear of } \\
\text { taking responsibility for others }\end{array}$ & $0.45^{* * *}$ & $0.26^{* * *}$ \\
\hline $\begin{array}{l}\text { Scale 5. Spiritual loneliness as a lack of } \\
\text { support, understanding }\end{array}$ & $0.57^{* * *}$ & $0.26^{* * *}$ \\
\hline $\begin{array}{l}\text { Scale 6. Loneliness due to external } \\
\text { unattractiveness }\end{array}$ & $0.45^{* * *}$ & $0.25^{* * *}$ \\
\hline \multicolumn{1}{|c|}{ General indicator } & $0.59^{* * *}$ & $0.26^{* * *}$ \\
\hline
\end{tabular}

Note: Significance level: ${ }^{* * *}-\mathrm{p}<0.001$

The presented correlation coefficients indicate that all types of loneliness experience, with the exception of the experience of loneliness as a temporary forced phenomenon, are associated with hopelessness, which is one of the most significant predictors of suicide and an important symptom of depression (Beck et al., 1985). Correlations with subjective well-being also suggest that experiencing loneliness as a temporary forced phenomenon causes the least damage to well-being and can be considered as the most constructive option. The greatestdamage to psychological well-being is caused by spiritual loneliness and the experience of loneliness as a negative phenomenon. In accordance with the assumption that loneliness is associated with personality traits that make it difficult to establish relationships, statistically significant correlation coefficients of the scales of loneliness experience with parameters of attachment style and social anxiety were also obtained (Table 5). The results obtained indicate that the experience of loneliness as a negative feeling is very typical for persons with high severity of anxiety, while avoidance does not show a connection with this type of experience. Likewise, experiencing loneliness as a temporary compulsion is associated with anxiety, but has nothing to do with avoidance. Other options for experiencing loneliness are associated with both avoidance and anxiety. 
Table 5: Correlation Coefficients of Loneliness Experience Scales with attachment style parameters and social anxiety $(\mathrm{N}=572)$.

\begin{tabular}{|c|c|c|c|}
\hline & Avoidance & Anxiety & Social anxiety \\
\hline Scale 1. Experiencing loneliness as a negative feeling & 0.07 & $0.42^{* * *}$ & $0.40^{* * *}$ \\
\hline Scale 2. Denying the experience of loneliness & $0.15^{* * *}$ & $0.19^{* * *}$ & $0.36^{* * *}$ \\
\hline $\begin{array}{l}\text { Scale 3. Experiencing loneliness as a temporary forced } \\
\text { phenomenon }\end{array}$ & 0.07 & $0.22^{* * *}$ & $0.28^{* * *}$ \\
\hline $\begin{array}{l}\text { Scale 4. Loneliness as a result of fear of taking } \\
\text { responsibility for others }\end{array}$ & $0.25^{* * *}$ & $0.17^{* * *}$ & $0.35^{* * *}$ \\
\hline $\begin{array}{l}\text { Scale 5. Spiritual loneliness as a lack of support, } \\
\text { understanding }\end{array}$ & $0.18^{* * *}$ & $0.35^{* * *}$ & $0.44^{* * *}$ \\
\hline Scale 6. Loneliness due to external unattractiveness & $0.21^{* * *}$ & $0.28^{* * *}$ & $0.39^{* * *}$ \\
\hline General indicator & $0.20^{* * *}$ & $0.34^{* * *}$ & $0.47^{* * *}$ \\
\hline
\end{tabular}

However, itcan be noted that loneliness as a result of fear of taking responsibility for others is somewhat more common in persons with high avoidance in relationships, while spiritual loneliness is more common in persons with high anxiety. In general, the various experiences associated with loneliness are more common in individuals with high levels of anxiety, although avoidance also shows a moderate connection. The revealed significant differences in the relationship of attachment parameters with different scales of loneliness experience are of particular interest due to the fact that the subjective feeling of loneliness according to the D. Russell and M. Ferguson scale is equally closely associated with both avoidance ( $\mathrm{r}=0.44 ; \mathrm{p}<0.001)$, and with concern ( $\mathrm{r}=0.51 ; \mathrm{p}<0.001)$. This means that individuals with different styles of insecure attachment suffer approximately equally from loneliness, but the nature of the experiences, associated with loneliness, they differ significantly. Thus, insecure attachment does indeed affect the content and severity of feelings associated with loneliness. Social anxiety and social phobia can also be seen as a significant factor in experiencing loneliness. The results of the correlation analysis obtained in this study are given in (Table. 4) testify in favor of this assumption. Social anxiety is closely related to the overall severity of the experience of loneliness, as well as to all types of experiences. It should be noted that social anxiety is most conducive to the experience of spiritual loneliness, as well as loneliness as a negative feeling.

\section{Linking loneliness to Demographic Characteristics}

The results of the analysis of the dependence of the experience of loneliness on gender, given in (Table 6), indicate that the experience of loneliness as a consequence of the fear of taking responsibility is equally characteristic of both women and men. However, other experiences associated with loneliness are more characteristic of women. The value of the Cohen's d-coefficients characterizing the effect size indicates that rather strong gender differences are found on the scales "Experiencing loneliness as a negative feeling" and "Experiencing loneliness as a temporary forced phenomenon." Compared to men, women are more likely to interpret loneliness as a negative condition. On the other hand, they are also more inclined to view loneliness as a temporary forced phenomenon. Given in (Table 7), the coefficients of correlation of indicators of loneliness with age indicate that the relationship between the experience of loneliness and age depends on gender. If men with age increase both the subjective feeling of loneliness and all the different variants of experiencing loneliness, then in women growth is noted only on the scale "Experiencing loneliness as a temporary forced phenomenon." Subjective feelings of loneliness and related experiences can be influenced by the presence or absence of close relationships.

Table 6: Gender differences on scales of experience of loneliness $(N=572)$.

\begin{tabular}{|c|c|c|c|c|c|c|c|}
\hline \multirow[t]{2}{*}{ Scales } & \multicolumn{2}{|c|}{$\begin{array}{c}\text { Men } \\
(\mathrm{N}=321)\end{array}$} & \multicolumn{2}{|c|}{$\begin{array}{l}\text { Women } \\
(\mathrm{N}=\mathbf{2 5 1})\end{array}$} & \multirow[t]{2}{*}{ t-value } & \multirow[t]{2}{*}{ p-level } & \multirow[t]{2}{*}{ d-Cohen } \\
\hline & $\mathbf{M}$ & SD & M & SD & & & \\
\hline Scale 1. Experiencing loneliness as a negative feeling & 6.97 & 2.66 & 8.62 & 3.80 & 6.08 & $<0.001$ & 0.51 \\
\hline Scale 2. Denying the experience of loneliness & 8.26 & 3.90 & 9.63 & 4.12 & 4.08 & $<0.001$ & 0.34 \\
\hline $\begin{array}{l}\text { Scale 3. Experiencing loneliness as a temporary } \\
\text { forced phenomenon }\end{array}$ & 10.02 & 4.21 & 11.82 & 4.48 & 4.92 & $<0.001$ & 0.41 \\
\hline $\begin{array}{l}\text { Scale 4. Loneliness as a result of fear of taking } \\
\text { responsibility for others }\end{array}$ & 7.69 & 3.58 & 7.89 & 3.67 & 0.67 & insignificant & 0.06 \\
\hline $\begin{array}{c}\text { Scale 5. Spiritual loneliness as a lack of support, } \\
\text { understanding }\end{array}$ & 7.36 & 3.25 & 8.37 & 3.73 & 3.46 & $<0.001$ & 0.29 \\
\hline Scale 6. Loneliness due to external unattractiveness & 6.79 & 2.88 & 7.33 & 3.33 & 2.09 & $<0.05$ & 0.18 \\
\hline General indicator & 47.09 & 16.10 & 53.66 & 17.40 & 4.68 & $<0.001$ & 0.39 \\
\hline
\end{tabular}

Note: $\mathrm{M}$ - mean value, SD - standard deviation, $\mathrm{t}$-value. - the value of the Student's t-test for independent samples 
Table 7: Correlation coefficients of indicators of the experience of loneliness with age.

\begin{tabular}{|c|c|c|c|}
\hline \multirow{2}{*}{ Indicators } & \multicolumn{3}{|c|}{ Age } \\
\hline & Women & Men & All \\
\hline Sample size N & 251 & 321 & 572 \\
\hline Scale 1. Experiencing loneliness as a negative feeling & 0.01 & $0.19 * * *$ & $0.09 *$ \\
\hline Scale 2. Denying the experience of loneliness & 0.09 & $0.26^{* * *}$ & $0.18^{* *}$ \\
\hline Scale 3. Experiencing loneliness as a temporary forced phenomenon & $0.15^{*}$ & $0.23^{* * *}$ & $0.19^{* *}$ \\
\hline Scale 4. Loneliness as a result of fear of taking responsibility for others & 0.01 & $0.17^{* *}$ & $0.09^{*}$ \\
\hline Scale 5. Spiritual loneliness as a lack of support, understanding & 0.00 & $0.24^{* * *}$ & $0.12^{* *}$ \\
\hline Scale 6. Loneliness due to external unattractiveness & -0.09 & $0.13^{*}$ & 0.02 \\
\hline General indicator & 0.05 & $0.26^{* * *}$ & $0.16^{* *}$ \\
\hline Subjective feeling of loneliness & 0.05 & $0.20^{* * *}$ & $0.12^{* *}$ \\
\hline
\end{tabular}

The results of one-way analysis of variance showed that the presence and type of relationships in which the subjects are members did not significantly affect the subjective feeling of loneliness according to the D. Russell and M. Ferguson scale (F (4, $551)=1.67, p$-insignificant). Most of the scales of the proposed questionnaire on the experience of loneliness also showed no dependence on the type of relationship, with the exception of the scale "Loneliness as a result of fear of taking responsibility" and "Loneliness due to external unattractiveness." In a visual form, the relationship between the type of relationship and indicators on these scales is shown in (Figure 2). The experience of loneliness as a result of the fear of taking responsibility is much more pronounced in persons who are not in a relationship or in an open relationship $(\mathrm{F}(4,551)=7.47 ; \mathrm{p}<0.001)$. For the same persons, the experience of loneliness is more characteristic due to their own unattractiveness $(F(4,551)=4.60 ; p=0.01)$. Since the distribution of men and women according to different types of relationships was quite significantly different (Table 1), in order to clarify the results obtained, the hypothesis about the interaction of a factor such as relationships with a gender factor was tested.

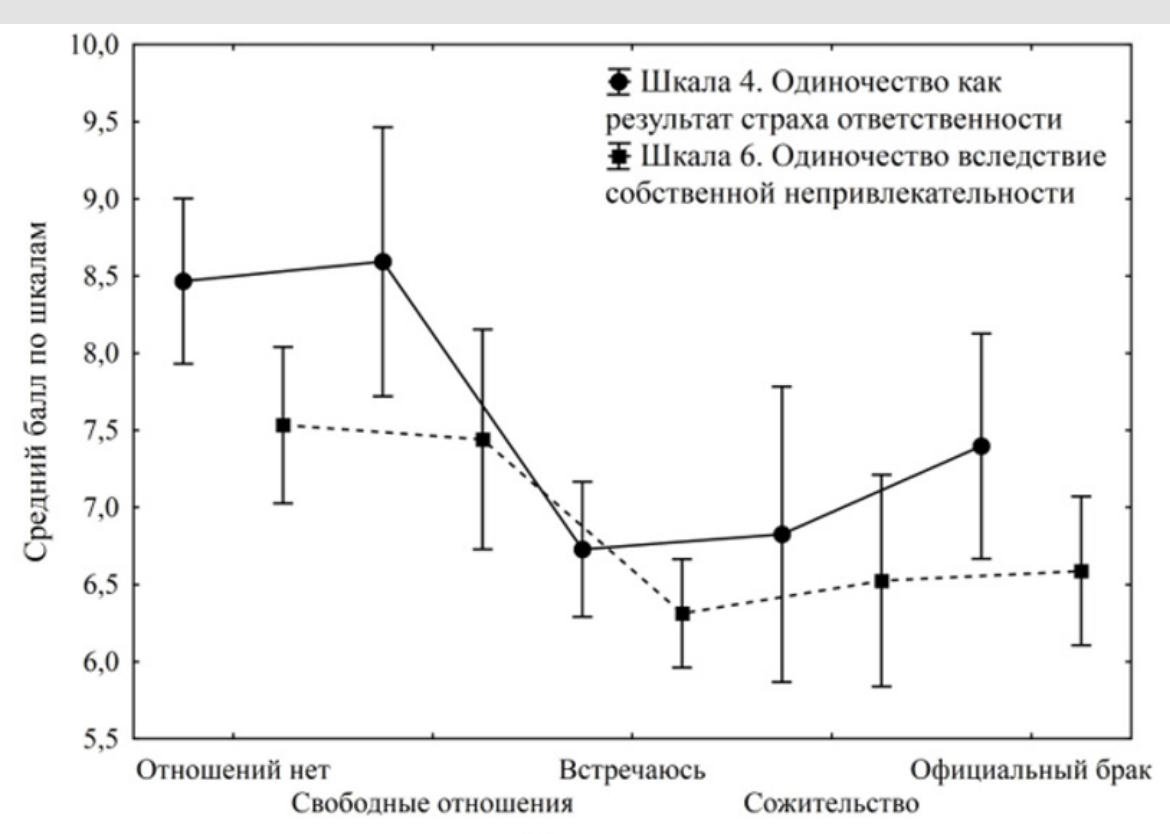

Тип отношений

Figure 2: Features of the experience of loneliness in groups with different types of close relationships according to the scales "Loneliness as a result of fear of taking responsibility" and "Loneliness due to external unattractiveness.

The results of two-way analysis of variance showed that the effect of interaction of the type of relationship with gender is not statistically significant for the scale "Loneliness as a result of fear of taking responsibility." Consequently, the tendency to attribute the reasons for their loneliness to a fear of responsibility in the absence of a serious relationship is equally characteristic of both men and women. At the same time, a statistically significant effect of the interaction of factors such as relationships and gender on indicators on the scale "Loneliness due to external unattractiveness" was found $(\mathrm{F}(4,546)=2.49, \mathrm{p}<0.05)$. This effect manifests itself, as can be seen 
from (Figure 3), in that it is more common for women to associate the reasons for their loneliness with their own unattractiveness in the absence of relationships or the presence of free relationships, while in men this tendency is not observed. This fact, obviously, reflects the great subjective significance of attractiveness as a factor in establishing relationships among women.

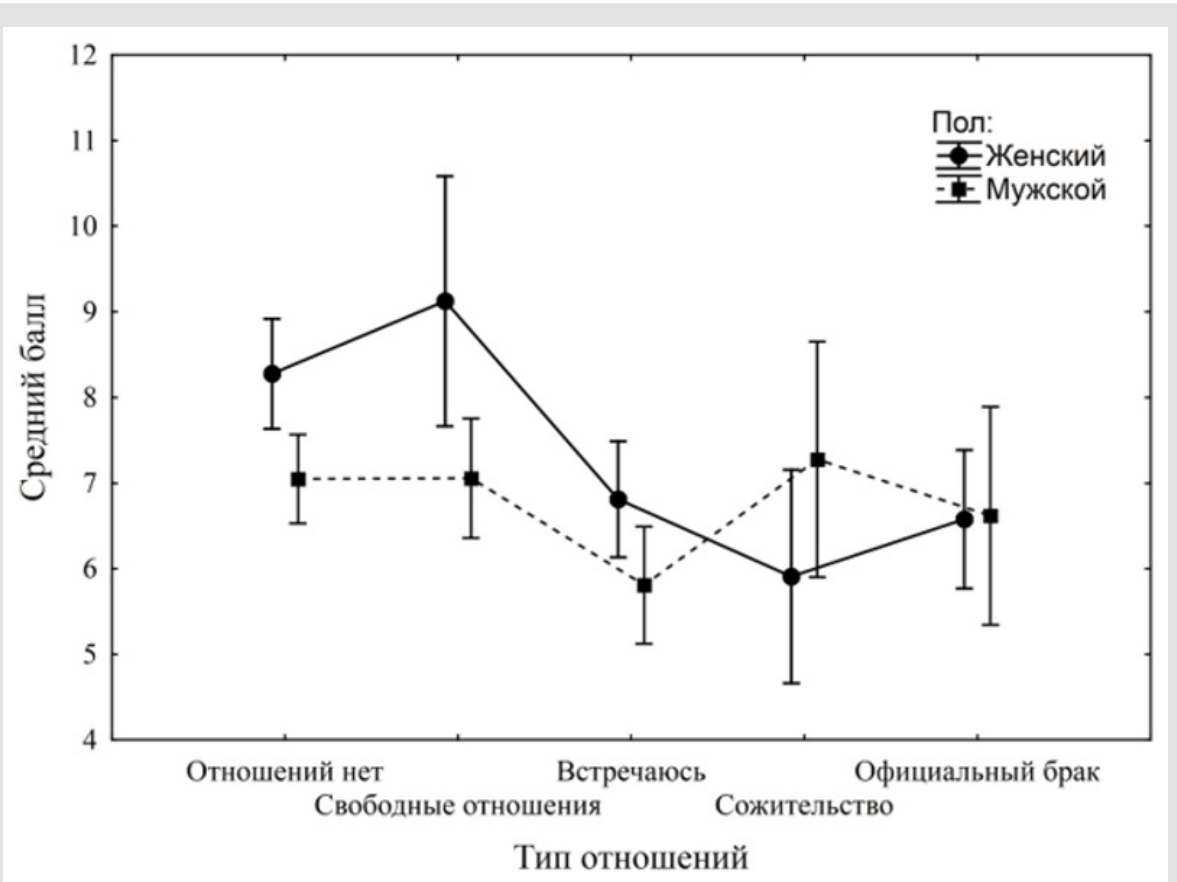

Figure 3: Features of the experience of loneliness in groups with different types of close relationships according to the scales "Loneliness as a result of fear of taking responsibility" and "Loneliness due to external unattractiveness.

\section{The Discussion of the Results}

Based on the results of previous research and theoretical analysis of the problem, six types of loneliness experiences were identified, which served as the basis for the theoretical structure of the proposed questionnaire. Empirical research has shown that the theoretical structure is well supported by confirmatory factor analysis, with all scales showing excellent internal consistency. Despite the close relationships between the scales, their relationships with other psychological variables (such as attachment style, subjective well-being, and hopelessness) and socio-demographic characteristics differ quite significantly, which suggests that it is justified to separate these aspects of the experience of loneliness the results of the study suggest that different types of loneliness experiences affect psychological well-being in different ways. In particular, the experience of loneliness as a temporary forced phenomenon causes the least damage to psychological wellbeing and does not provoke a state of hopelessness. Therefore, this version of the experience of loneliness is the most constructive. At the same time, experiences of loneliness as a negative state or a state associated with a lack of understanding and support greatly reduce the well-being of the individual and contribute to the emergence of hopelessness, which increases the risk of suicidal behavior. These findings are of interest in the context of psychological counseling, allowing to outline ways to develop skills for constructive coping with the problem of loneliness.
Of interest is the fact that in this study, unlike some previous ones Andersson [11], it was not possible to identify the connection between the subjective feeling of loneliness and the presence of close relationships and their type. Probably, this fact is explained by the predominance of student youth in the sample: in this age period, the absence of stable close relationships can be compensated for by the extensive contacts with peers, many of whom are not yet burdened with family and can devote a lot of time to friendly communication. At the same time, the results of the analysis on the scales of the new questionnaire demonstrated the presence of features of the experience of loneliness in persons who are in relationships of different types. In particular, young men and women who are not in serious relationships are more likely to associate the reasons for their loneliness with the fear of taking responsibility. In addition, it is more common for girls who do not have a serious relationship to consider their own external unattractiveness as one of the reasons. Consequently, while there is no difference in the level of loneliness between those who are in serious relationships and those who are who are not in them, there are clear differences in how people interpret the reasons for loneliness. Obviously, in the absence of relationships, such reasons are more often found in oneself - in the fear of responsibility and in their own external unattractiveness (among girls).

The results obtained are convincing that the proposed questionnaire makes it possible to in-depth analysis of the 
experiences associated with loneliness, allowing to characterize ideas about its causes and to determine the severity of negative emotions caused by it. The structure of the questionnaire does not duplicate the composition of other methods for diagnosing a subjective feeling of loneliness and related experiences Ishmukhametov, et al. $[3,19]$, providing an opportunity to measure new, previously not considered, but of significant interest aspects of the experience of loneliness. This allows us to hope that the proposed method will be in demand both in the activities of practical psychologists and in further scientific research on the problem of loneliness.

\section{Attachment}

Loneliness Experience Questionnaire Instruction: Instruction. Read each statement carefully and assess to what extent it applies to you. We ask you to rate each statement on a five-point scale as follows: almost never -1 , rarely - 2 , from time to time -3 , often - 4 , almost always - 5 .

1. When I am lonely, it seems to me that life is passing by.

2. Loneliness is the most comfortable state for me.

3. Temporary loneliness helps me to understand myself, my feelings, and relationships with myself and with others.

4. It is easier to be alone than to constantly care and worry about someone.

5. I feel lonely that I do not feel support in my endeavors.

6. The reason for my loneliness is that many people find me unattractive.

7. The feeling of loneliness makes me feel sorry for myself.

8. I do not need communication; it is more comfortable for me to be alone.

9. Experiencing loneliness at times, I have learned to put up with it.

10. It is more convenient for me to be alone (alone) than to build a serious relationship with another person.

11. I feel lonely, as my opinion always goes unheard.

12. If I were as attractive as most other people, then I would not suffer from loneliness.

13. From my loneliness I often want to cry.

14. I like to spend time alone and never visit.

15. In the period of loneliness, I read a lot of psychological literature, listen to music, and am interested in art.

16. Fear of responsibility prevents me from developing close relationships with other people.

17. I feel lonely because many people around me are too childish, and I have no one to share something important.

18. I am sure that external unattractiveness is one of the main reasons for loneliness.

19. Alone I experience an inner struggle with a sense of emptiness.

20. I always prefer to walk alone down the street

21. I am sure that the period of loneliness will lead me to a new stage in my life.

22. I prefer solitude because I do not want to put in the effort to establish and maintain a serious relationship.

23. I often feel lonely because no one understands me.

24. I feel lonely, because of my unattractiveness I do not succeed.

25. When I am lonely, I feel unnecessary.

26. I like to spend my leisure time alone.

27. I try to consider loneliness as a resource for selfdevelopment, despite the discomfort.

28. I'd rather be alone than waste time and energy on the hassle of living together with someone.

29. My ideas are not taken seriously or supported by others, so I feel lonely.

30. I am very lonely, because of my unattractiveness, many do not even try to get to know me for real.

\section{Key}

(Key 1).

Key 1: All statements are straight forward, so the final score is obtained by summing the scores for the statements included in the scale.

\begin{tabular}{|l|c|}
\hline \multicolumn{1}{|c|}{ Scales } & Statement numbers \\
\hline $\begin{array}{l}\text { Scale 1. Experiencing loneliness as a negative } \\
\text { feeling }\end{array}$ & 17131925 \\
\hline Scale 2. Denial of the experience of loneliness & 28142026 \\
\hline $\begin{array}{l}\text { Scale 3. Experiencing loneliness as a temporary } \\
\text { forced phenomenon }\end{array}$ & 39152127 \\
\hline $\begin{array}{l}\text { Scale 4. Loneliness as a result of fear of taking } \\
\text { responsibility for others }\end{array}$ & 410162228 \\
\hline $\begin{array}{l}\text { Scale 5. Spiritual loneliness as a lack of support, } \\
\text { understanding }\end{array}$ & 511172329 \\
\hline $\begin{array}{l}\text { Scale 6. Physical loneliness due to one's own } \\
\text { unattractiveness }\end{array}$ & 612182430 \\
\hline
\end{tabular}




\section{References}

1. Statistics of VCIOM (All-Russia Public Opinion Research Center): Love or Loneliness - What is Prevail-ing in the Life of Russians.

2. Erikson E (1996) Identity: Youth and Crisis. Moscow: Progress.

3. Ishmukhametov IN (2006) Psychometric Properties of Loneliness Scale UCLA (ver-sion 3): Study in University Students. Computer Modelling and New Technologies 10(3): 89-95.

4. Mikulincer M, Shaver PR (2014) An Attachment Perspective on Loneliness. In: RJ Coplan, JC Bowker (Eds.)., The Handbook of Solitude: Psychological Perspectives on Social Iso-lation, Social Withdrawal, and Being Alone. Chichester, West Sussex, UK: John Wiley \& Sons, p. 34-50.

5. Berlin LJ, Cassidy J, Belsky J (1995) Loneliness in Young Children and Infant-Mother At-tachment: A Longitudinal Study. Merrill-Palmer Quarterly 41(1): 91-103.

6. Givertz M, Woszidlo A, Segrin C, Knutson K (2013) Direct and indirect effects of attachment orientation on relationship quality and loneliness in married couples. Journal of Social and Personal Relationships 30(8): 1096-1120.

7. Kryukova TL (2016) The Psychology of the Coping with Loneliness. Psychological Studies 9(49): 1

8. Cacioppo JT, Patrick W (2008) Loneliness: Human nature and the need for social connection. New York, NY, US: WW Norton \& Company.

9. In: Pierce GR, Sarason BR, Sarason IG (Eds.)., (1996) Handbook of Social Support and the Family. Boston, MA: Springer US.

10. Myers D (2007) Social Psychology: Intensive Course. St. Petersburg: Praim-Evroznak.

11. Osin EN, Leont'ev DA (2013) Differential Questionnaire of Experiencing of Loneliness: Structure and properties. Psychology. Journal of Higher School of Economics 10(1): 55-81.

12. Andersson L (1998) Loneliness research and interventions: A review of the literature. Aging \& Mental Health 2(4): 264-274.

13. Perlman D, Russell D (2004) Loneliness and health. In: B кн. N. B. Andeson (Edt.)., Encyclope-dia of health \& behavior 2: 585-589.

14. Tiikkainen P, Heikkinen RL, Leskinen E (2004) The structure and stability of perceived to-getherness in elderly people during a 5-year follow-up. Journal of Applied Gerontology 23(3): 279-294.

\section{ISSN: 2574-1241}

DOI: 10.26717/BJSTR.2021.36.005800

EA Manakova. Biomed J Sci \& Tech Res

(C) This work is licensed under Creative BY Commons Attribution 4.0 License

Submission Link: https://biomedres.us/submit-manuscript.php
15. Slobodchikov IM (2006) Theoretical and Experimental Study of Loneliness (in adolescents). PhD dissertation, Russian State University for Humanities, Moscow.

16. Kupersmidt JB, Sigda KB, Sedikides C, Voegler ME (1999) Social selfdiscrepancy theory and loneliness during childhood and adolescence. In: K Rotenberg, S Hymel (Eds.)., Loneliness in childhood and adolescence, pp. 263-279.

17. Vasilyuk FE (1984) The Psychology of Experiencing: The Resolution of Life's Critical Situations. Moscow: Moscow University Press.

18. Manakova EA (2015) Types of Experiencing of Loneliness in the Context of Psychological Health of Female Students. PhD dissertation, Moscow State University of Psychology and Education, Moscow.

19. Osin EN, Leont'ev DA (2013) Differential Questionnaire of Experiencing of Loneliness: Structure and properties. Psychology. Journal of Higher School of Economics 10(1): 55-81.

20. Cherepukhin YuM (1995) Attitudes toward Family in Alone Men. Sociological Journal 1: 159-165.

21. Krasnikova OM (2015) Loneliness. Moscow: Nikeya.

22. Sokolova MV (1996) The Scale of Subjunctive Well-being. Yaroslavl': NPTs «Psikhodiagnostika».

23. Beck AT, Weissman A, Lester D, Trexler L (1974) The measurement of pessimism: The hopelessness scale. Journal of Consulting and Clinical Psychology 42(6): 861-865.

24. Beck AT, Steer RA, Kovacs M, Garrison B (1985) Hopelessness and eventual suicide: A 10-year prospective study of patients hospitalized with suicidal ideation. The American Journal of Psychiatry 142(5): 559563.

25. Sabel'nikova NV, Kashirskii DV (2015) The Questionnaire of Attachment to Close People. Psychological Journal 36(4): 84-97.

26. Brennan KA, Clark CL, Shaver PR (1998) Self-report measurement of adult attachment: An integrative overview. In: JA Simpson, WS Rholes (Eds.)., Attachment theory and close relationships. New York, NY, US: Guilford Press, USA, pp. 46-76.

27. Sagalakova OA, Truevtsev DV (2012) The Ques-tionnaire of Social Phobia. Clinical Psychology in Rus-sia 4(15).

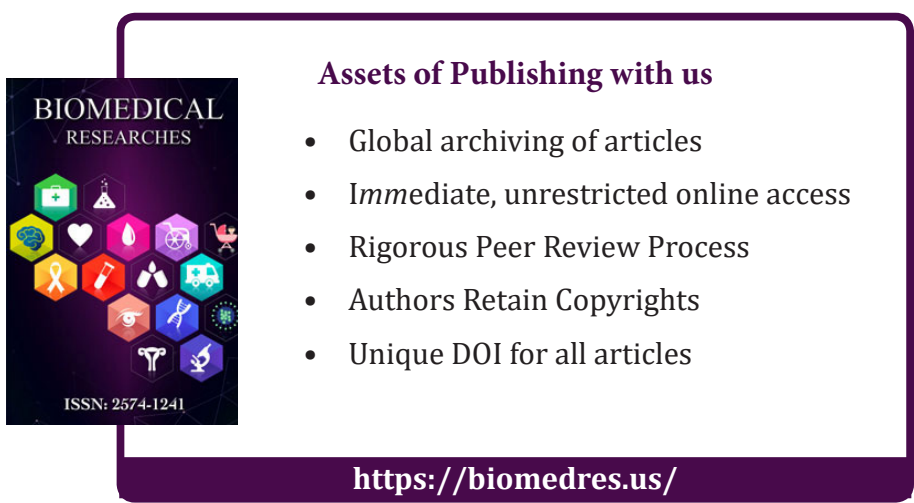

